\begin{tabular}{|l|l|l|}
\hline \multicolumn{2}{|c|}{ PublisherInfo } \\
\hline \hline PublisherName & $:$ & BioMed Central \\
\hline \hline PublisherLocation & $:$ & London \\
\hline \hline PublisherImprintName & $:$ & BioMed Central \\
\hline \hline
\end{tabular}

\title{
Do differences in probability of survival affect study design in ICU?
}

\begin{tabular}{|c|c|c|}
\hline \multicolumn{3}{|c|}{ ArticleInfo } \\
\hline ArticleID & \multicolumn{2}{|l|}{4313} \\
\hline ArticleDOI & \multicolumn{2}{|c|}{ 10.1186/ccf-2001-73401 } \\
\hline ArticleCitationID & \multicolumn{2}{|l|}{73401} \\
\hline ArticleSequenceNumber & \multicolumn{2}{|l|}{24} \\
\hline ArticleCategory & \multicolumn{2}{|l|}{ Paper Report } \\
\hline ArticleFirstPage & \multicolumn{2}{|l|}{1} \\
\hline ArticleLastPage & \multicolumn{2}{|l|}{3} \\
\hline ArticleHistory & $\begin{array}{l}\text { RegistrationDate } \\
\text { Received } \\
\text { OnlineDate }\end{array}$ & $\begin{array}{l}2001-12-5 \\
2001-8-23 \\
2001-12-5\end{array}$ \\
\hline ArticleCopyright & \multicolumn{2}{|c|}{ Biomed Central Ltd2001 } \\
\hline ArticleGrants & & \\
\hline
\end{tabular}




\begin{tabular}{|l|l|l|}
\hline ArticleContext & $:$ & 1305455 \\
\hline
\end{tabular}

Adrian Mellor, ${ }^{\text {Aff1 }}$

Aff1 Portsmouth, UK

Keywords

Experimental design, probability of survival, scoring methods, trauma

\section{Context}

Despite advances in theoretical knowledge, many large prospective trials of novel therapies in trauma and critical care provide disappointing results. This may, in part, be because the wrong patients are included (i.e. those with very high probability of death) or because the therapy may not affect survival but still improve outcome. The early termination of two recent trials has highlighted two main problems with studies in critically ill patients: firstly, it may not be ethical to recruit patients to these trials unless the subgroups who may benefit can be more clearly defined; secondly large amounts of resources are wasted on failed trials. It is therefore very important to understand the nature of the disease, patient disparity, and the effect of the distribution of the probability of survival when testing hypotheses.

\section{Significant findings}

Trauma patients (those retrieved by SAMU, Paris, France) had a bimodal distribution of probability of survival (Ps), with peaks at $\mathrm{Ps}<0.1$ and Ps $>0.9$. The heterogeneity in the probability of survival had a marked effect on the study size required, depending on whether the study was powered for the percentage of survivors or the individual chances of survival (e.g. for a drug that increases the probability of survival by $20 \% n=63,202$ versus $n=2848$ respectively). This discrepancy occurred with $\mathrm{J}$ shaped distributions to a lesser extent. This could be overcome by identifying factors that place patients in an intermediate Ps group.

\section{Comments}


This paper is an interesting piece of work, which highlights some of the pitfalls of study design in intensive care. It should be read by anyone contemplating a major study of outcomes in the critically ill. The overestimation of power is most likely to occur with a bimodal distribution of Ps as in this case and would be less marked with other distributions. It would suggest that we should only recruit patients with similar Ps, rather than taking a mean value across the study population

\section{Methods}

A retrospective database analysis. Trauma and injury severity scoring used to ascertain Ps of 350 trauma patients. Simulation of a therapeutic trial.

\section{Additional information}

\section{References}

1. Riou B, Landais P, Vivien B, Stell P, Labbene I, Carli P: Distribution of probability of survival is a strategic issue for randomized controlled trials in critically ill patients. Anesthesiology. 2001, 95: 56-63.

This PDF file was created after publication. 